\title{
Integrating biocompatible chemistry and manipulating cofactor partitioning in metabolically engineeredLactococcus lactisfor fermentative production of (3S)-acetoin
}

\author{
Liu, Jianming; Solem, Christian; Jensen, Peter Ruhdal
}

Published in:

Biotechnology and Bioengineering

Link to article, DOI:

10.1002/bit.26038

Publication date:

2016

Document Version

Peer reviewed version

Link back to DTU Orbit

Citation (APA):

Liu, J., Solem, C., \& Jensen, P. R. (2016). Integrating biocompatible chemistry and manipulating cofactor partitioning in metabolically engineeredLactococcus lactisfor fermentative production of (3S)-acetoin. Biotechnology and Bioengineering, 113(12), 2744-2748. https://doi.org/10.1002/bit.26038

\section{General rights}

Copyright and moral rights for the publications made accessible in the public portal are retained by the authors and/or other copyright owners and it is a condition of accessing publications that users recognise and abide by the legal requirements associated with these rights.

- Users may download and print one copy of any publication from the public portal for the purpose of private study or research.

- You may not further distribute the material or use it for any profit-making activity or commercial gain

- You may freely distribute the URL identifying the publication in the public portal 
Integrating biocompatible chemistry and manipulating cofactor partitioning in metabolically engineered Lactococcus lactis for fermentative production of (3S)-acetoin ${ }^{\dagger}$

\author{
Jianming Liu, Christian Solem*, Peter Ruhdal Jensen*
}

National Food Institute, Technical University of Denmark, DK-2800 Kgs. Lyngby, Denmark.

Running title: Harnessing biocompatible chemistry for efficient production of (3S)-acetoin

*Corresponding author: Peter Ruhdal Jensen

National Food Institute, Technical University of Denmark, DK-2800 Kgs. Lyngby, Denmark;

telephone: +45 45252510; fax: +45 45932809; e-mail: perj@food.dtu.dk

Christian Solem

National Food Institute, Technical University of Denmark, DK-2800 Kgs. Lyngby, Denmark;

telephone: +45 45252510; fax: +45 45932809; e-mail: chso@food.dtu.dk

${ }^{\dagger}$ This article has been accepted for publication and undergone full peer review but has not been through the copyediting, typesetting, pagination and proofreading process, which may lead to differences between this version and the Version of Record. Please cite this article as doi: [10.1002/bit.26038] 


\section{Abstract}

Biocompatible chemistry (BC), i.e. non-enzymatic chemical reactions compatible with living organisms, is increasingly used in conjunction with metabolically engineered microorganisms for producing compounds that do not usually occur naturally. Here we report production of one such compound, $(3 S)$-acetoin, a valuable precursor for chiral synthesis, using a metabolically engineered Lactococcus lactis strain growing under respiratory conditions with ferric iron serving as a BC component. The strain used has all competing product pathways inactivated, and an appropriate cofactor balance is achieved by fine-tuning the respiratory capacity indirectly via the hemin concentration. We achieve high-level $(3 S)$-acetoin production with a final titer of $66 \mathrm{mM}(5.8 \mathrm{~g} / \mathrm{L})$ and a high yield ( $71 \%$ of the theoretical maximum). To the best of our knowledge, this is the first report describing production of ( $3 S$ )-acetoin from sugar by microbial fermentation, and the results obtained confirm the potential that lies with $\mathrm{BC}$ for producing useful chemicals. This article is protected by copyright. All rights reserved

\section{Keywords}

Metabolic engineering; biocompatible chemistry; (3S)-acetoin; cofactor partitioning 
Biocompatible chemistry $(\mathrm{BC})$ is emerging as a promising new field, due to the potential that lies in having non-enzymatic chemical reactions extending the chemistry of living organisms (Wallace and Balskus, 2014). In conjunction with metabolically engineered microorganisms capable of producing various compounds, the usefulness of $\mathrm{BC}$ becomes even more apparent. Recent examples include cyclopropanation of microbially produced styrene (Wallace and Balskus, 2015) and the production of diacetyl and $(S, S)$-2,3-butanediol (Liu et al., 2016).

Herein, we report how $\mathrm{BC}$ combined with metabolic engineering allows us to produce $(3 S)$-acetoin, an important stereoisomer of acetoin with many applications, e.g. for synthesis of novel optically active $\alpha$ hydroxyketone derivatives, pharmaceutical precursors and liquid crystal composites (Xiao and Lu, 2014). (3R)-acetoin, the enantiomer of (3S)-acetoin, can be formed readily from pyruvate by enzymatic reactions involving $\alpha$-acetolactate synthase (ALS) and $\alpha$-acetolactate decarboxylase (ALDB) and efficient production of this isomer has been reported previously, either using naturally occurring or engineered microorganisms (Wang et al., 2015; Zhang et al., 2014; Zhang et al., 2016). (3S)-acetoin is difficult to prepare using purely enzymatic transformations, but can be formed from diacetyl or meso2,3-butanediol as reported by Ui et al., 1984 and Gao et al., 2013, who used non-growing cells as biocatalyst. One of the challenges of making $(3 S)$-acetoin has been the low levels of its precursor diacetyl, which is formed by non-enzymatic oxidative decarboxylation (ALOX) of $\alpha$-acetolactate. $\alpha$ Acetolactate is not stable and decarboxylates spontaneously into an enolate anion, which is followed by nucleophilic reactions in the presence of $\mathrm{O}_{2}$ and then finally gives rise to diacetyl (Fig. 1). For this reason, it seems that a promising strategy for making $(3 S)$-acetoin would involve metabolically engineering an efficient $\alpha$-acetolactate producing cell factory that expresses a suitable $(3 S)$-acetoin forming diacetyl reductase (DAR), in combination with BC for speeding up the ALOX transformation of $\alpha$-acetolactate into diacetyl (Fig. 1). Another challenge is to find a solution for the cofactor 
imbalance which arises, when $(3 S)$-acetoin is formed from glucose and leads to a surplus of one NADH (Fig.1). All these issues could hinder the development of an efficient cell factory for high-level production by direct microbial fermentation.

Lactococcus lactis has been demonstrated to have great potential as a production organism for a broad range of interesting chemicals, due to its high glycolytic flux, well-characterized metabolic network and ease of genetic manipulation (Mazzoli et al., 2014). Normally L. lactis does not respire because it lacks a complete biosynthetic pathway for hemin (or protoporphyrin), an essential component of the cytochrome oxidase in the electron transport chain (ETC) (Lechardeur et al., 2011), however the respiration machinery can be fully functional if hemin is available from the environment, as all the other components of the ETC, such as the membrane-bound NADH dehydrogenase, menaquinone biosynthetic enzymes, and a cytochrome $b d$ oxidase, are present. There are several ways in which $L$. lactis can benefit from having an active respiration, e.g. it has been reported that tolerance to oxidative stress is enhanced and that biomass formation is stimulated (Koebmann et al., 2008). Respiration has also been demonstrated to be an excellent way to re-oxidize NADH (Liu et al., 2016).

We recently demonstrated that L. lactis can be converted into an efficient diacetyl producer (Liu et al., 2016). We successfully inactivated almost all alternative product pathways by deleting genes encoding lactate dehydrogenases (LDH), phosphotransacetylase (PTA), alcohol dehydrogenase (ADHE), butanediol dehydrogenases (ButBA), $\alpha$-acetolactate decarboxylase (ALDB) and additionally inactivated the cytoplasmic NADH oxidase (NoxE) to optimize biomass formation. These efforts gave rise to CS4616m (MG1363 $\Delta^{3} l d h \Delta p t a \Delta a d h E \Delta b u t B A \Delta a l d B \Delta n o x E$ ), which was fully able to reoxidize the surplus NADH through respiration, and most of the carbon flux $(>80 \%)$ was directed to $\alpha$ acetolactate/diacetyl. The $\alpha$-acetolactate formed could subsequently be converted into diacetyl by adding either $\mathrm{Fe}^{3+}, \mathrm{Fe}^{2+}$ or $\mathrm{Cu}^{2+}$. By introducing a robust diacetyl reductase (DAR), sourced from Enterobacter cloacae (Li et al., 2012), into CS4616m, we obtained a strain CS4701m that readily 
accumulated (2S,3S)-butanediol (SBDO) (Fig. 2A) under non-respiratory conditions (Liu et al., 2016). Since formation of SBDO from diacetyl consumes two NADH, whereas formation of $(3 S)$-acetoin only requires one, a way to dispose of surplus NADH is needed in order to be able to produce $(3 S)$-acetoin (Fig. 2A). One strategy that was used in Escherichia coli involved fine-tuning respiration by modulating the ubiquinone biosynthetic pathway (Wu et al., 2015), and this approach enabled highyield lactate production under fully aerobic conditions. In L. lactis, due to the incomplete ETC caused by an incomplete hemin-biosynthesis pathway (Fig. 2A), the same effect could perhaps be achieved by adjusting the hemin concentration in the medium.

To test this we carried out preliminary growth experiments in test tubes, where CS4701m was grown in M17 medium (Terzaghi and Sandine, 1975) with $43 \mathrm{mM}$ glucose, $6 \mathrm{mM} \mathrm{Fe} \mathrm{s}^{3+}$ and different hemin concentrations ranging from 0 to $5 \mu \mathrm{g} / \mathrm{ml}$, and analyzed the product composition after $24 \mathrm{~h}$ of fermentation. Without hemin we found that SBDO was the main product as expected, and that the SBDO concentration decreased gradually with increasing hemin concentration (Table 1). Adding as little as $0.05 \mu \mathrm{g} / \mathrm{ml}$ hemin had a remarkable effect on product composition, where the amount of SBDO formed was reduced by $82 \%$ (from $35 \mathrm{mM}$ to $6.3 \mathrm{mM}$ ), while the $(3 S)$-acetoin concentration increased from $1.1 \mathrm{mM}$ to $27.3 \mathrm{mM}$. At $0.2 \mu \mathrm{g} / \mathrm{ml}$ hemin, the $(3 S)$-acetoin concentration peaked at $31.8 \mathrm{mM}(2.8$ $\mathrm{g} / \mathrm{L})$ with a yield of $0.50 \mathrm{C}$-mol/C-mol of glucose, corresponding to $74 \%$ of the theoretical maximum (Table 1). As expected, beyond this hemin concentration both (3S)-acetoin and SBDO formation were reduced, and at $5 \mu \mathrm{g} / \mathrm{ml}$ hemin, the dominant product was diacetyl $(25.0 \mathrm{mM})$ and only $23 \%$ of the carbon flux ended up as (3S)-acetoin (Table 1). This trend was also consistent with our observations from shake flasks (30 $\mathrm{ml}$ of working volume $/ 250 \mathrm{ml}$ ) and we achieved a high yield of $(3 S)$-acetoin $(84 \%)$ at the same hemin level of $0.2 \mu \mathrm{g} / \mathrm{ml}$ hemin (Table 1). The hemin concentration did not only affect product formation, but also the final cell density $\left(\mathrm{OD}_{600}\right)$, which increased from 2.1 without hemin to around 3.0 at $0.2 \mu \mathrm{g} / \mathrm{ml}$ hemin, which is a $48 \%$ increase. As demonstrated by Blank et al. 
(Blank et al., 2001), L. lactis can save some of the ATP normally used by the ATPase for generating the essential proton gradient by having an active respiration (Fig. 2A), and this additional ATP leads to an increased biomass yield which can be useful for increasing productivity, as the biomass serves as the catalyst.

These preliminary experiments clearly demonstrated that it was feasible to fine-tune the respiratory capacity of $L$. lactis for (3S)-acetoin formation by adjusting the hemin concentration (Fig. 2B). When using test tubes or shake flasks, it is difficult to ensure that sufficient oxygen is available, especially at high cell densities. In order to examine this more closely, additional experiments were carried out using bioreactors (Sartorius Biostat Q, $500 \mathrm{ml}$ working volume, equipped with Clark electrode), where the dissolved oxygen (DO) level could be easily monitored. When the hemin concentration was $0.2 \mu \mathrm{g} / \mathrm{ml}$, the DO level (Fig. 2C, curve I) declined slightly from 100\% saturation to $78 \%$ during the first $6 \mathrm{~h}$ and then gradually increased to around $90 \%$. Thus, at this hemin concentration, respiration is unlikely to alter the DO level to an extent that would affect growth or product formation. At $3 \mu \mathrm{g} / \mathrm{ml}$ hemin the DO level was drastically reduced (Fig. 2C, curve III) during the first $5 \mathrm{~h}$, and diacetyl was the main fermentation product demonstrating that at this hemin concentration respiration was overly active and could oxidize more of the NADH generated in glycolysis. At the intermediate hemin concentration of $0.5 \mu \mathrm{g} / \mathrm{ml}$, the DO level at all times was in between that observed for 0.2 and $3 \mu \mathrm{g} / \mathrm{ml}$ (Fig. 2C, curve II). Besides monitoring the $\mathrm{DO}$ level, the $\mathrm{NADH} / \mathrm{NAD}^{+}$ratio was also determined in order to estimate the intracellular redox state. For hemin concentrations between 0 and $1 \mu \mathrm{g} / \mathrm{ml}$, a linear correlation between the $\mathrm{NADH} / \mathrm{NAD}^{+}$ratio and specific growth rate could be observed, and in this range it was possible to partition the NADH between DAR and respiration, and thereby control the strain's capacity for both cell growth and the product composition. Without hemin, the NADH/NAD ${ }^{+}$ratio was high (0.08) and the strain grew relatively slowly $\left(\mu=0.1 \mathrm{~h}^{-1}\right)$ (Fig. 2D), which indicated that the nonenzymatic ALOX flux was limiting and dictated a low SBDO production rate. At hemin concentrations 
above $1 \mu \mathrm{g} / \mathrm{ml}$, the opposite was observed, and a low NADH/NAD ${ }^{+}$ratio $(0.025)$ coincided with a high specific growth rate $\left(\mu=0.75 \mathrm{~h}^{-1}\right)$. This indicates that under these conditions respiration could efficiently re-oxidize NADH, thus making it unavailable for diacetyl reduction, and therefore only small amounts of $(3 S)$-acetoin accumulated (Table 1, Fig. 2). The NADH/NAD ${ }^{+}$at which $(3 S)$-acetoin reached the highest level was 0.065 , and this corresponded to a hemin concentration of $0.2 \mu \mathrm{g} / \mathrm{ml}$ (Fig. 2D).

For this reason the remaining characterization was carried out using $0.2 \mu \mathrm{g} / \mathrm{ml}$ hemin. We found that within the first $12 \mathrm{~h}$, nearly all the glucose (90\%) had been completely consumed and the final cell density $\left(\mathrm{OD}_{600}\right)$ of 2.9 had been reached (Fig. 3A). Surprisingly (3S)-acetoin only constituted a small fraction of the fermentation products present $(5 \mathrm{mM})$, and the remaining products were $\alpha$-acetolactate $(20 \mathrm{mM})$ and SBDO (10.5 mM) (Fig. 3A). Over the next $12 \mathrm{~h}$ the $\alpha$-acetolactate and SBDO were gradually converted into $(3 S)$-acetoin, which finally reached $34.5 \mathrm{mM}(3.0 \mathrm{~g} / \mathrm{L})$ with a high yield 0.56 C-mol/C-mol of glucose ( $80 \%$ of the theoretical maximum). To see if it was possible to increase the titer further we doubled the glucose concentration to $93 \mathrm{mM}$, using the same hemin concentration $(0.2$ $\mu \mathrm{g} / \mathrm{ml}$ ), and observed the same trend as demonstrated using bioreactors (Fig. 3B). For this experiment we used shake flask conditions as a preliminary test. A $(3 S)$-acetoin titer of $66 \mathrm{mM}(5.8 \mathrm{~g} / \mathrm{L})$ was obtained, with a slightly reduced production yield (71\%) when compared to the bioreactor conditions, which indicates that the hemin concentration may require further optimization when the glucose concentration is increased.

The accumulation of $\alpha$-acetolactate and SBDO which we observed in the first phase, probably was caused by a limiting ALOX flux from $\alpha$-acetolactate to diacetyl, despite the presence of $\mathrm{Fe}^{3+}$. One possibility could be to increase the $\mathrm{Fe}^{3+}$ concentration, however, there are drawbacks associated with this as $\mathrm{Fe}^{3+}$ also can have a negative effect on growth. When we increased the $\mathrm{Fe}^{3+}$ concentration to 10 
$\mathrm{mM}$, this only had a small effect on the ALOX flux (data not shown), and a better solution probably is to find a more efficient catalyst.

We did not observe any obvious formation of diacetyl during the course of fermentation, which demonstrates that the DAR was sufficiently active to allow for instantaneous conversion of the diacetyl generated into $(3 S)$-acetoin and SBDO. Apparently, when the respiration capacity is limited $(0.2 \mu \mathrm{g} / \mathrm{ml}$ hemin), the cells first convert diacetyl into SBDO to regenerate $\mathrm{NAD}^{+}$, which helps sustain a higher glycolytic flux and faster growth, and subsequently the accumulated $\alpha$-acetolactate and SBDO are converted into $(3 S)$-acetoin, probably due to respiration becoming limiting at high cell densities.

To the best of our knowledge, this is the first report describing the fermentative production of $(3 S)$ acetoin from glucose. This was achieved by using an approach not previously described, involving metabolic engineering, $\mathrm{BC}$ and co-factor partitioning by titrating the hemin concentration. The applied strategy could be very interesting for synthesis of other valuable chemicals, which are not easily obtained by conventional organic synthesis or pure enzymatic transformations.

\section{Materials and Methods}

\section{Strains}

CS4701m (MG1363 $\Delta^{3} l d h \triangle p t a \triangle a d h E \Delta b u t B A \Delta a l d B \Delta n o x E$, pJM001) is a derivative of the plasmidfree strain Lactococcus lactis subsp. cremoris MG1363 (Gasson, 1983). The plasmid pJM001, which is based on pTD6 (Solem et al., 2013), includes a synthetic codon-optimized dar (diacetyl reductase, accession no. JN035909) from Enterobacter cloacae with a high strength promoter (Liu et al., 2016).

\section{Hemin optimization}

The hemin optimization experiment was performed in tubes, shake flasks and subsequently, bioreactors. We used M17 medium (Oxoid, England) supplemented with $43 \mathrm{mM}$ glucose and $6 \mathrm{mM} \mathrm{Fe}{ }^{3+}$ for all the conditions. The strain CS4701m was first grown in a $25 \mathrm{ml}$ tube with $5 \mathrm{ml}$ of working volume and different concentrations of hemin (stock solution $0.5 \mathrm{mg} / \mathrm{ml}$ in $0.05 \mathrm{M} \mathrm{NaOH}$ ) for initial optimization. 
Then shake flask fermentation (250 ml conical flasks with $30 \mathrm{ml}$ of working volume) was carried out. All the cultivation was carried out at $30^{\circ} \mathrm{C}$ and $200 \mathrm{rpm}$. In order to monitor the dissolved oxygen (DO) levels in the fermentation process and enable large scale production, the bioreactors (Sartorius Biostat Q, $500 \mathrm{ml}$ working volume) were used with a constant stirring speed (150 rpm) and a constant low aeration rate around $0.02 \mathrm{vvm}$. The $\mathrm{DO}$ and $\mathrm{pH}$ were monitored during the process and samples were collected periodically for determining cell density $\left(\mathrm{OD}_{600}\right)$, glucose, $\alpha$-acetolactate, diacetyl, $(3 S)$ acetoin and SBDO concentrations. Tetracycline is kept at $5 \mu \mathrm{g} / \mathrm{ml}$ for the engineered strain.

\section{DNA techniques}

The plasmid pCS1966 was used for deleting genes in L. lactis (Solem et al., 2008). The genes including three lactate dehydrogenase homologs $(l d h)$, phosphotransacetylase $(p t a)$, alcohol dehydrogenase $(a d h E)$, butanediol dehydrogenases (butBA), $\alpha$-acetolactate decarboxylase (aldB) and NADH oxidase

(noxE) have been successfully knocked out in our previous work (Solem et al., 2013; Liu et al., 2016). The respiration of L. lactis can be activated by the addition of hemin (or protoporphyrin), which is an essential cofactor of the cytochrome $b d$ oxidase in the electron transport chain (Koebmann et al., 2008).

\section{Analytical methods}

Cell growth was regularly monitored by measuring $\mathrm{OD}_{600}$ and quantification of glucose, $(3 S)$-acetoin and SBDO was carried out using an Ultimate 3000 high-pressure liquid chromatography system (Dionex, Sunnyvale, USA) equipped with a Aminex HPX-87H column (Bio-Rad, Hercules, USA) and a Shodex RI-101 detector (Showa Denko K.K., Tokyo, Japan). The column oven temperature was set at $60^{\circ} \mathrm{C}$ and the mobile phase consisted of $5 \mathrm{mM} \mathrm{H}_{2} \mathrm{SO}_{4}$, at a flow rate of $0.5 \mathrm{ml} / \mathrm{min}$. Diacetyl and $\alpha-$ acetolactate were measured colorimetrically using a method developed by Benson et al. (Benson et al., 1996) and Westerfeld (Westerfeld, 1945). The methods for extraction of NADH and NAD ${ }^{+}$were described by Liu et al., 2016 and quantification of $\mathrm{NADH} / \mathrm{NAD}^{+}$ratio were performed using the kit $\mathrm{NAD}_{+} / \mathrm{NADH}-\mathrm{Glo}^{\mathrm{TM}}$ assay (Promega). 


\section{References}

Benson KH, Godon JJ, Renault P, Griffin HG, Gasson MJ. 1996. Effect of ilvBN-encoded $\alpha$ acetolactate synthase expression on diacetyl production in Lactococcus lactis. Appl. Microbiol. Biotechnol. 45:107-111.

Blank LM, Koebmann BJ, Michelsen OLE, Nielsen LK. 2001. Hemin reconstitutes proton extrusion in an $\mathrm{H}^{+}$-ATPase-negative mutant of Lactococcus lactis. J. Bacteriol. 183:6707-6709.

Gao J, Xu YY, Li FW, Ding G. 2013. Production of S-acetoin from diacetyl by Escherichia coli transformant cells that express the diacetyl reductase gene of Paenibacillus polymyxa ZJ-9. Lett. Appl. Microbiol. 57:274-281.

Gasson MJ. 1983. Plasmid complements of Streptococcus lactis NCDO 712 and other lactic streptococci after protoplast-induced curing. J. Bacteriol. 154:1-9.

Koebmann B, Blank LM, Solem C, Petranovic D, Nielsen LK, Jensen PR. 2008. Increased biomass yield of Lactococcus lactis during energetically limited growth and respiratory conditions. Biotechnol. Appl. Biochem. 50:25-33.

Lechardeur D, Cesselin B, Fernandez A, Lamberet G, Garrigues C, Pedersen M, Gaudu P, Gruss A. 2011. Using heme as an energy boost for lactic acid bacteria. Curr. Opin. Biotechnol. 22:143-149.

Li L, Wang Y, Zhang L, Ma C, Wang A, Tao F, Xu P. 2012. Biocatalytic production of (2S,3S)-2,3butanediol from diacetyl using whole cells of engineered Escherichia coli. Bioresour. Technol. $115: 111-116$.

Liu J, Chan S.H.J, Block-Nannestad T, Chen J, Lee SY, Solem C, Jensen P.R. 2016. Combining metabolic engineering and biocompatible chemistry for high-yield production of homo-diacetyl and homo-(S,S)-2,3-butanediol. Metab. Eng. 36:57-67.

Mazzoli R, Bosco F, Mizrahi I, Bayer E, Pessione E. 2014. Towards lactic acid bacteria-based biorefineries. Biotechnol. Adv. 32:1216-1236.

This article is protected by copyright. All rights reserved 
Solem C, Dehli T, Jensen PR. 2013. Rewiring Lactococcus lactis for ethanol production. Appl. Environ. Microbiol. 79:2512-2518.

Terzaghi BE, Sandine WE. 1975. Improved medium for lactic streptococci and their bacteriophages. Appl. Microbiol. 29:807-813.

Ui S, Masuda H, Muraki H. 1984. Laboratory-scale production of acetoin isomers (D(-) and L(+)) by bacterial fermentation. J. Ferment. Technol. 62:151-156.

Wallace S, Balskus EP. 2014. Opportunities for merging chemical and biological synthesis. Curr. Opin. Biotechnol. 30:1-8.

Wallace S, Balskus EP. 2015. Interfacing microbial styrene production with a biocompatible cyclopropanation reaction. Angew. Chemie Int. Ed. 54:7106-7109.

Wang D, Zhou J, Chen C, Wei D, Shi J, Jiang B, Liu P, Hao J. 2015. R-acetoin accumulation and dissimilation in Klebsiella pneumoniae. J. Ind. Microbiol. Biotechnol. 42:1105-1115.

Westerfeld WW. 1945. A colorimetric determination of paraldehyde. J. Lab. Clin. Med. 30:1076.

Wu H, Bennett GN, San K-Y. 2015. Metabolic control of respiratory levels in coenzyme Q biosynthesis-deficient Escherichia coli strains leading to fine-tune aerobic lactate fermentation. Biotechnol. Bioeng. 112:1720-1726.

Xiao Z, Lu JR. 2014. Strategies for enhancing fermentative production of acetoin: a review. Biotechnol. Adv. 32:492-503.

Zhang L, Liu Q, Ge Y, Li L, Gao C, Xu P, Ma C. 2016. Biotechnological production of acetoin, a biobased platform chemical, from a lignocellulosic resource by metabolically engineered Enterobacter cloacae. Green Chem. 18:1560-1570.

Zhang X, Zhang R, Bao T, Rao Z, Yang T, Xu M, Xu Z, Li H, Yang S. 2014. The rebalanced pathway significantly enhances acetoin production by disruption of acetoin reductase gene and moderateexpression of a new water-forming NADH oxidase in Bacillus subtilis. Metab. Eng. 23:34-41.

This article is protected by copyright. All rights reserved 


\section{Figure legends}

Figure 1 Combination of metabolic engineering and biocompatible chemistry for (3S)-acetoin production. CS4701m (MG1363 $\Delta^{3} l d h \Delta p t a \Delta a d h E \Delta b u t B A \Delta a l d B \Delta n o x E$, pJM001 (expressing DAR)) was constructed (Liu et al., 2016) and used for this purpose. The proposed mechanism for the nonenzymatic oxidative decarboxylation from $\alpha$-acetolactate to diacetyl is illustrated. Abbreviation: LDH, lactate dehydrogenase; PTA, phosphotransacetylase; ADHE, alcohol dehydrogenase; ButBA, butanediol dehydrogenases; ALDB, $\alpha$-acetolactate decarboxylase; ALS, $\alpha$-acetolactate synthase; NoxE, NADH oxidase. DAR: diacetyl reductase from Enterobacter cloacae; ETC, electron transport chain; NoxAB, NADH dehydrogenases; Cyt bd, cytochrome $b d$ oxidase.

Figure 2 Cofactor partitioning through the regulation of hemin concentration. (A) The 2 NADH (per glucose) formed in glycolysis can be re-oxidized in two ways, either via DAR (diacetyl reductase from E. cloacae) to $(3 S)$-acetoin/SBDO or by the electron transport chain, where the activity of the latter can be finely controlled by hemin levels in the medium. (B) HPLC chromatograms illustrating the formation of diacetyl ( $\mathrm{R}=18.9 \mathrm{~min}),(3 \mathrm{~S})$-acetoin $(\mathrm{R}=20.1 \mathrm{~min})$ and $(2 \mathrm{~S}, 3 \mathrm{~S})$-butanediol $(\mathrm{R}=22.0 \mathrm{~min})$ at different concentrations of hemin. R means retention time. (C) The dissolved oxygen (DO) levels monitored during the fermentation process under different hemin concentrations. Curve I: $0.2 \mu \mathrm{g} / \mathrm{ml}$; Curve II: $0.5 \mu \mathrm{g} / \mathrm{ml}$ (the drop of DO circled was caused by the addition of antifoam); Curve III: 3 $\mu \mathrm{g} / \mathrm{ml}$. The fermentation details were described in Materials and Methods. (D) The NADH/NAD ${ }^{+}$ratio and $\mu$ (specific growth rate) as a function of hemin concentration. Experiments were conducted in duplicate and error bars indicate standard deviations.

This article is protected by copyright. All rights reserved 
Figure 3 Microbial fermentation for efficient production of (3S)-acetoin. (A) CS4701m (MG1363 $\Delta^{3} l d h \triangle p t a \triangle a d h E \triangle b u t B A \Delta a l d B \Delta$ noxE, pJM001 (expressing DAR)) was grown in M17 medium with $43 \mathrm{mM}$ glucose, $6 \mathrm{mM} \mathrm{Fe}{ }^{3+}$ and $0.2 \mu \mathrm{g} / \mathrm{ml}$ hemin in bioreactors. Experiments were conducted in duplicate and error bars indicate standard deviations. (B) CS4701m was tested in $93 \mathrm{mM}$ glucose, 6 $\mathrm{mM} \mathrm{Fe}^{3+}$ and $0.2 \mu \mathrm{g} / \mathrm{ml}$ hemin (Shake flasks). Experiments were conducted in duplicate and error bars indicate standard deviations.

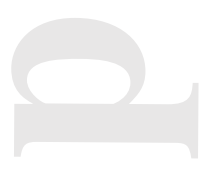


Table 1 Optimization of hemin concentrations for strain CS4701 $\mathrm{m}^{1}$

\begin{tabular}{cccccccc}
\hline \multicolumn{2}{c}{$\begin{array}{c}\text { Hemin } \\
(\mu \mathrm{g} / \mathrm{ml})\end{array}$} & OD $_{600}$ & Diacetyl & $(2 S, 3 S)$-Butanediol & $(3 S)$-Acetoin & Yield $^{2}$ & Yield $^{3}$ \\
\cline { 4 - 8 } & & \multicolumn{3}{c}{$(\mathrm{mM})$} & & C-mol/C-mol of glucose \\
\hline 0 & $(\mathrm{~T})$ & 2.1 & 0.0 & 35.0 & 1.1 & 0.01 & 0.02 \\
$0.05(\mathrm{~T})$ & 3.1 & 0.7 & 6.3 & 27.3 & 0.42 & 0.63 \\
0.1 & $(\mathrm{~T})$ & 3.0 & 2.0 & 1.1 & 30.0 & 0.47 & 0.70 \\
0.2 & $(\mathrm{~T})$ & 3.1 & 1.7 & 0.6 & 31.8 & 0.50 & 0.74 \\
0.5 & $(\mathrm{~T})$ & 2.9 & 12.0 & 0.0 & 25.5 & 0.40 & 0.59 \\
3 & $(\mathrm{~T})$ & 3.5 & 18.9 & 0.0 & 16.2 & 0.25 & 0.38 \\
5 & $(\mathrm{~T})$ & 3.8 & 25.0 & 0.0 & 10.0 & 0.15 & 0.23 \\
0 & $(\mathrm{~F})$ & 1.9 & 0.0 & 33.1 & 1.9 & 0.03 & 0.04 \\
0.1 & $(\mathrm{~F})$ & 3.1 & 2.2 & 2.7 & 30.0 & 0.47 & 0.70 \\
0.2 & $(\mathrm{~F})$ & 3.1 & 0.2 & 0.2 & 36.1 & 0.56 & 0.84 \\
0.5 & $(\mathrm{~F})$ & 3.5 & 15.7 & 0.0 & 21.9 & 0.34 & 0.51 \\
3 & $(\mathrm{~F})$ & 4.0 & 20.1 & 0.0 & 18.5 & 0.29 & 0.43 \\
0.2 & $(\mathrm{~B})$ & 2.9 & 3.2 & 0.1 & 34.5 & 0.54 & 0.80 \\
0.5 & $(\mathrm{~B})$ & 3.8 & 18.0 & 0.0 & 19.7 & 0.31 & 0.46 \\
3 & $(\mathrm{~B})$ & 4.1 & 21.1 & 0.0 & 15.5 & 0.24 & 0.36 \\
\hline
\end{tabular}

, CS4701m (MG1363 $\Delta^{3} l d h \Delta p t a \Delta a d h E \Delta b u t B A \Delta a l d B \Delta n o x E$, pJM001 (expressing DAR)) was grown in M17 medium with $43 \mathrm{mM}$ glucose, $6 \mathrm{mM} \mathrm{Fe}^{3+}$ and different concentrations of hemin. The optimization was performed in Tubes (T), Shake flasks (F) and Bioreactors (B). The samples were collected after $24 \mathrm{~h}$ fermentation. The experiments were conducted two times, while the deviations were within $\pm 10 \% .^{2}$, yield for $(3 S)$-Acetoin based on C-mol/C-mol of glucose. ${ }^{3}$, yield for $(3 S)$-Acetoin based on the theoretical maximum $0.67 \mathrm{C}$-mol/C-mol of glucose $\left(\mathrm{CO}_{2}: 0.33 \mathrm{C}\right.$-mol/C-mol of glucose $)$. 


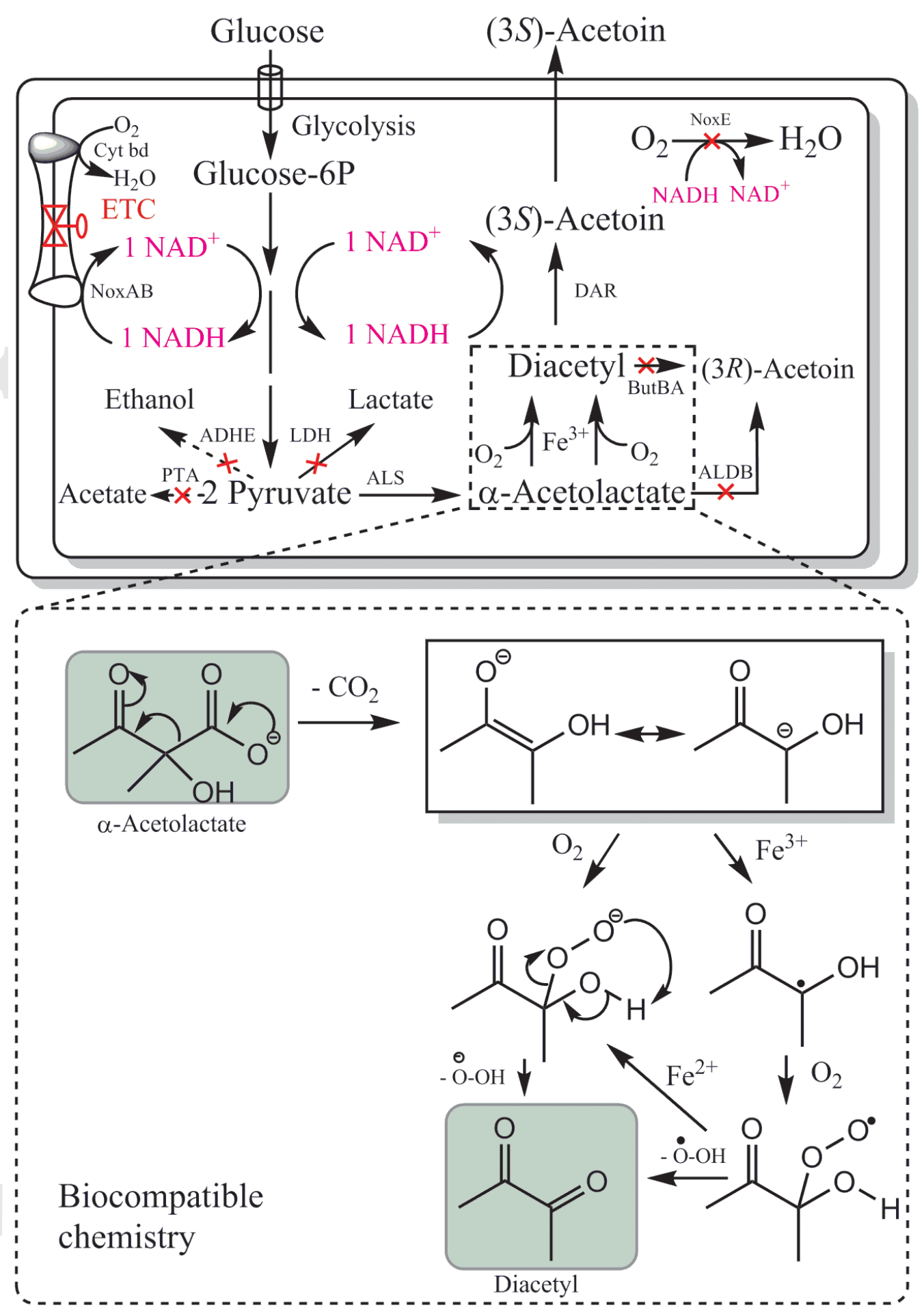

Figure 1 

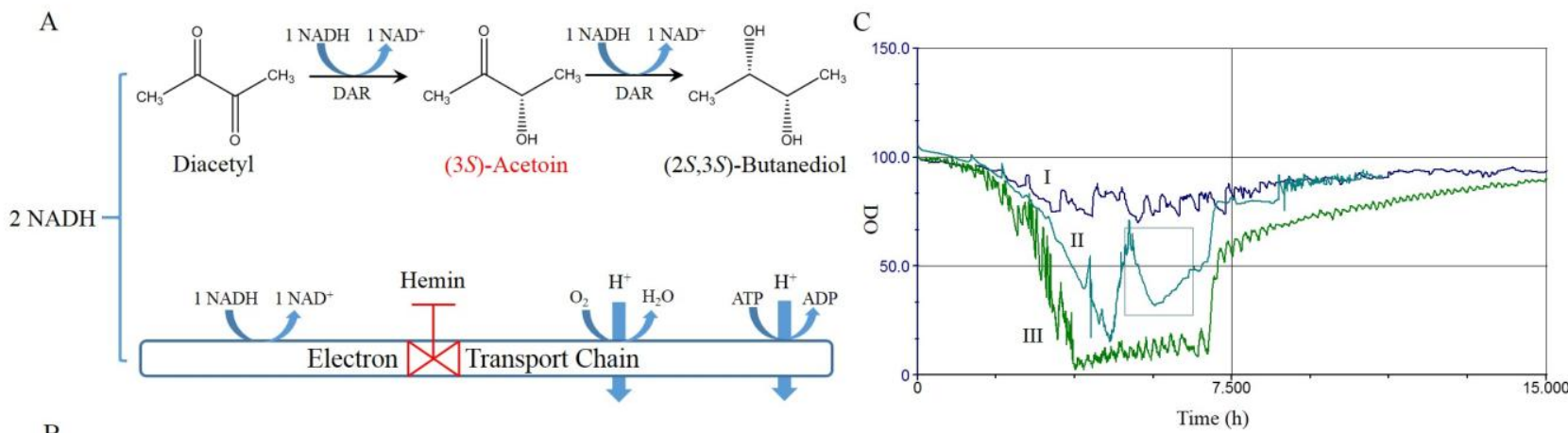

B
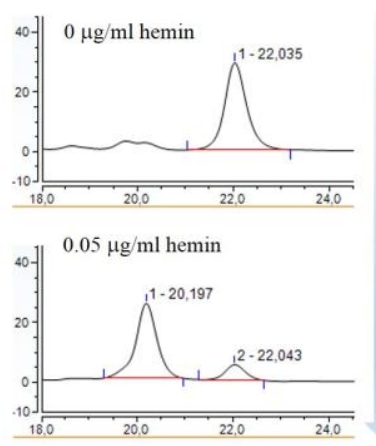
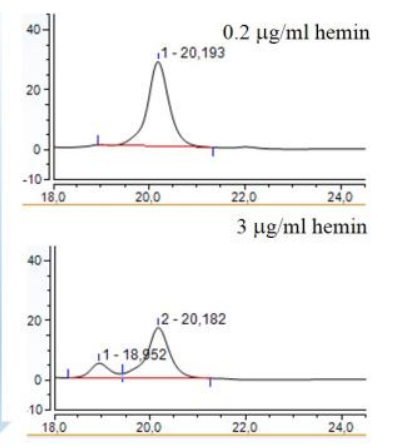

D

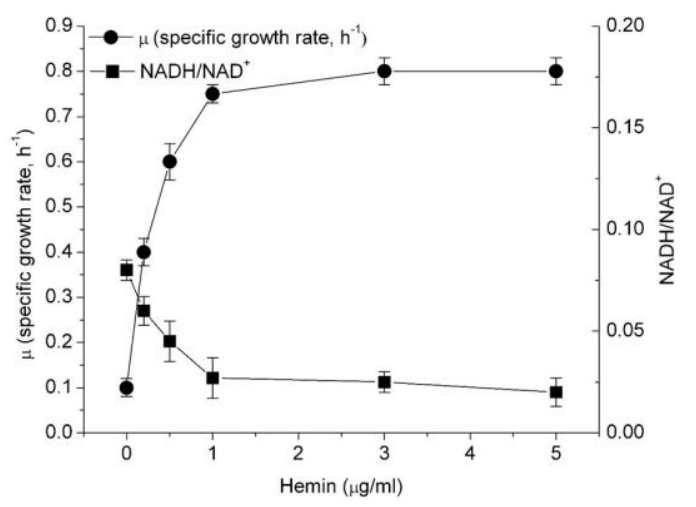

Figure 2 
A

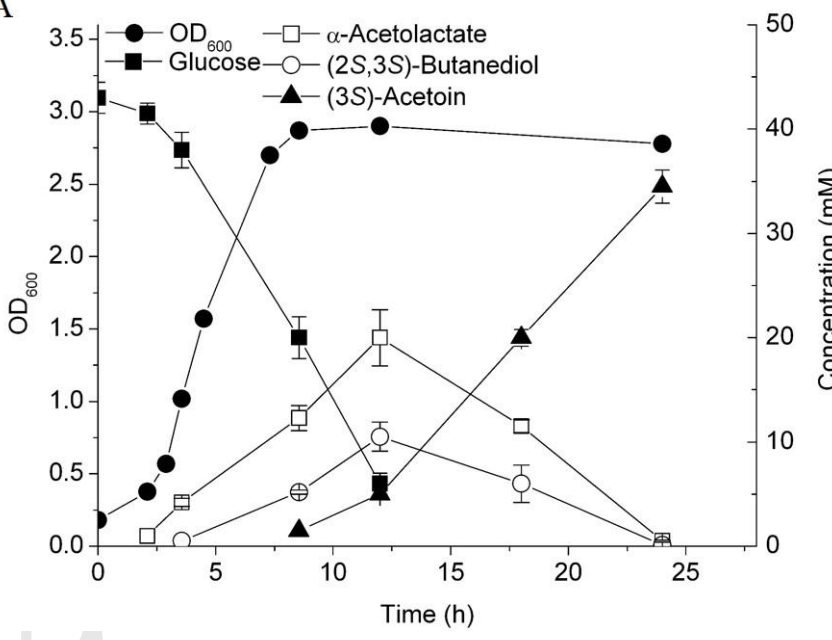

B

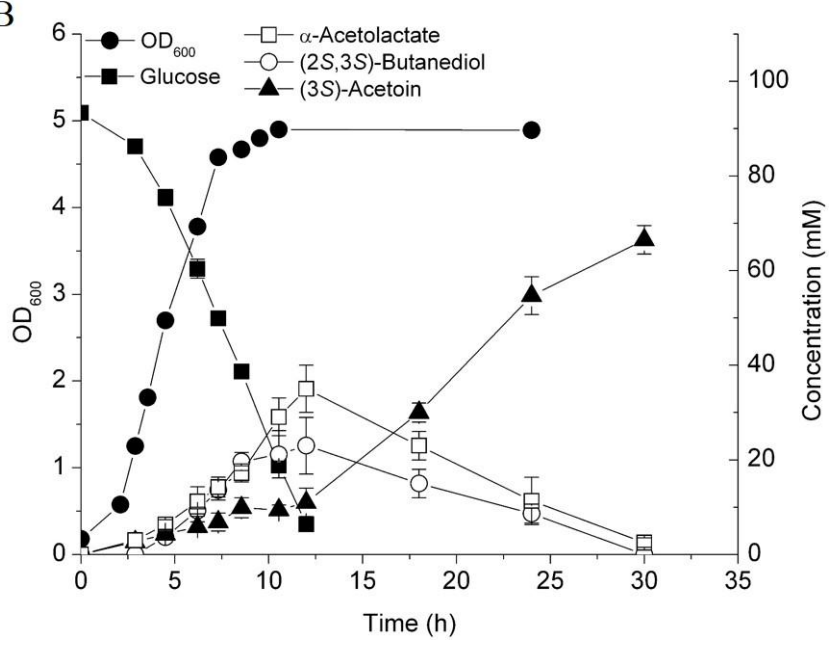

Figure 3 